\title{
Ultrasound-guided prostate biopsy: indication, morbidity and outcome at Hopital General Idrissa Pouye
}

\author{
Modou Ndiaye 1* $^{*}$, Mouhamed Jalloh², Madina Ndoye², Samba Thiapato Faye ${ }^{3}$, Saint Charles Nabab Kouka , \\ Ndiaga Seck Ndour' ${ }^{1}$, Mouhamadou Moustapha Mbodji², El Hadji Malick Diaw', Ibrahima Louis Mane², \\ Issa Labou ${ }^{2}$, Lamine Niang ${ }^{2}$ and Serigne Magueye Gueye ${ }^{2}$
}

\begin{abstract}
Background: Magnetic resonance imaging (MRI)-guided prostate biopsy has a higher sensitivity than the ultrasound-guided biopsy, but its realization requires a dedicated interventional MRI, specific material, which is not available in our context; hence, ultrasound-guided biopsy remains of great interest. Currently, ultrasound-guided biopsy outside of a clinical trial is the gold standard for the diagnosis of prostate cancer. The objective of our work is to evaluate our practice of transrectal ultrasound-guided prostate biopsy using an endorectal probe by describing the technique and evaluating the morbidity and results.

Methods: This is a descriptive study of ultrasound-guided prostatic biopsies performed over a 2-year period. The parameters studied were frequency of the procedure, age, rectal examination findings, total PSA level, prostate biopsy morbidities and results. Descriptive statistics were performed, and comparison of qualitative variables was made by the Chi-square test with statistical significance set for $a<5 \%$

Results: Two hundred and thirty-one patients were included over a two-year period. The mean age of our patients was $65 \pm 8.2$ years. Rectal examination finding was suspicious in $36.9 \%$ and the median total PSA was $19.8 \mathrm{ng} / \mathrm{ml}$ $(0.1-5936 \mathrm{ng} / \mathrm{ml})$. Seventy-seven percent of patients reported their pathology results. Prostatic adenocarcinoma was the most common finding accounting for $53.7 \%$ of results. Complications were observed in 16 patients (6.9\%) with a predominance of initial hematuria, voiding pain and fever.
\end{abstract}

Conclusion: In our series, the cancer detection rate was significant and the complications rate was acceptable at $6.9 \%$.

Keywords: Ultrasound, Biopsy, Prostate cancer, Morbidity

\section{Background}

Prostate biopsy with pathology examination confirms the diagnosis of prostate cancer. The biopsy is indicated if there is an abnormality of the digital rectal examination and/or an elevation of the total PSA level. This is an invasive procedure with an overall morbidity between 3 and

\footnotetext{
*Correspondence: ndiaymodou87@gmail.com

1 Service d'urologie CHU Aristide Le Dantec de Dakar, Dakar, Senegal Full list of author information is available at the end of the article
}

$23 \%$ and an exceptional but not zero mortality $[1,2]$. For a long time, the procedure was digitally guided transrectally. Comparatively, there is a greater sensitivity of ultrasound-guided biopsy for the diagnosis of prostate cancer making that procedure recommended for the confirmation of prostate cancer [3, 4]. Mbassi et al. [5] had found in them a higher sensitivity of the ultrasound-guided biopsy compared to the finger-guided one (61.8 and 38.3 $(p=0.006)$, respectively). Schoot et al. [6] in their study had shown that the magnetic resonance imaging-guided 
prostate biopsy and transrectal ultrasound-guided prostate biopsy did not significantly differ in overall prostate cancer detection (sensitivity 0.85 and 0.81 , respectively). The realization for MRI-guided prostate biopsy requires a dedicated interventional MRI, specific material, which is not available in our context, hence ultrasound-guided biopsy remains of great interest. The objective of our work is to highlight our practice of prostate biopsy using an endorectal probe in order to describe the technique and evaluate the morbidity and results of the ultrasoundguided prostate biopsy.

\section{Methods}

This was a cross-sectional descriptive study of 231 patients who underwent an ultrasound-guided prostate biopsy between November 1, 2015, and October 31, 2017 , in our center. All patients who underwent transrectal ultrasound-guided prostate biopsy during the study period were included. Patients who underwent a digitally guided prostate biopsy and a transperineal biopsy were excluded. Each patient was informed of the importance and complications of biopsy. Antibiotic prophylaxis was given by a single oral fluoroquinolone two hour before the procedure or by a third-generation cephalosporin if the patient had previously received antibiotic therapy. Rectal preparation with Sodium dihydrogenphosphate dihydrate and sodium hydrogenphosphate dodecahydrate by a cleansing enema the day before at 10 p.m and the morning of the biopsy at 6 a.m was systematic. The patient was placed in a lithotomy position under local anesthesia $(10 \mathrm{ml}$ of $20 \%$ xylocaine urethral gelly $10 \mathrm{~min}$ before the biopsy). A Logiq $\mathrm{C} 2$ brand ultrasound machine was used. The ultrasound transrectal probe was a $7 \mathrm{MHz}$ multiplanar electronic probe.

A 20-cm-length, thin needle of $18 \mathrm{G}$ Type "tru-Cut" length and a metallic guide were used. The rest of the equipment included a core collection box containing Formalin 10\%, sterile gloves, condoms and ultrasound jelly. Twelve biopsy cores were sampled at the following locations: two from the base, two from the middle and two from the prostatic apex of each prostatic lobe. In addition, sampling of palpable nodules at digital rectal examination and hypoechoic areas was also performed. In some cases where the total PSA level and locally advanced tumor, the number of cores sampled was two in each lobe. The parameters studied were frequency, age, digital rectal examination, total PSA level, histological results and morbidity. For the assessment of morbidity, patients were followed up for 2 weeks. Data analysis was done with IBM SPSS Statistic 20 software. We performed descriptive statistics with median calculations (interquartile range) for quantitative variables. The comparison of
Table 1 Annual distribution of the number of diagnosed cancers, consultations and prevalence

\begin{tabular}{llllll}
\hline Year & 2013 & 2014 & 2015 & 2016 & 2017 \\
\hline Number of diagnosed cancer & 53 & 48 & 43 & 40 & 49 \\
Annual number of consultations & 6395 & 6225 & 5508 & 5967 & 5081 \\
Annual prevalence & 0.7 & 0.8 & 0.8 & 0.7 & 0.8 \\
\hline
\end{tabular}

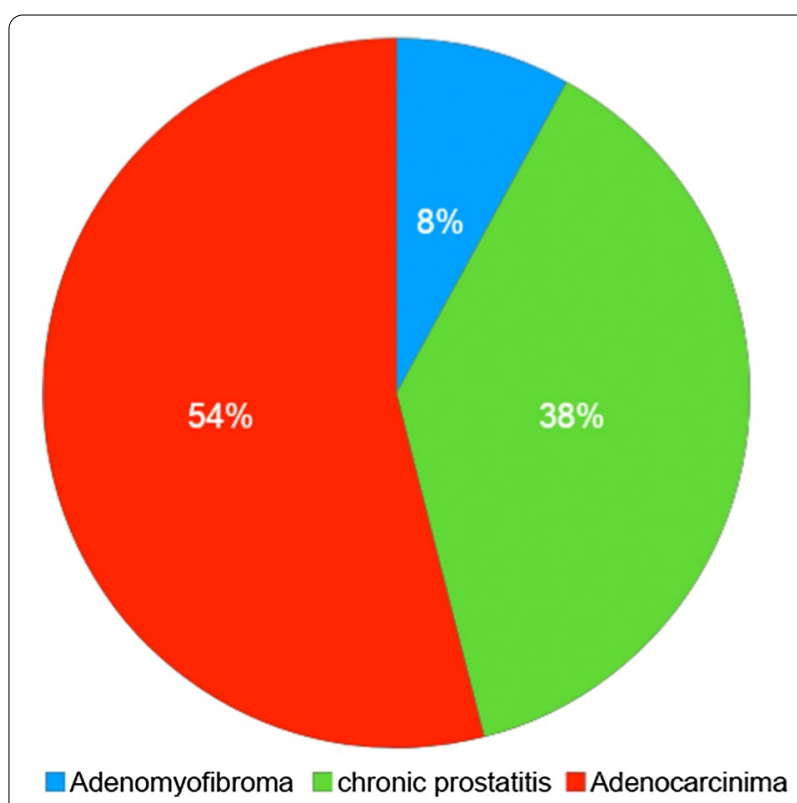

Fig. 1 Distribution of pathology results of patients who underwent transrectal ultrasound-guided prostate biopsy $(n=177)$

qualitative variables was made by the Chi-square test. Statistical significance was considered for $\alpha<5 \%$.

\section{Results}

Two hundred and thirty-one patients were included over a two-year period, with a mean annual frequency of 115.5. The mean age of the patients was $65 \pm 8.2$ years. The most represented age group was [60, 70 years].

The symptoms of lower urinary tract (LUTS) were the most frequent reason for referral (Table 1).

Digital rectal examination showed prostate induration in $22.9 \%$ (53) of patients, a multinodular prostate in $16.4 \%$ (38) of patients, an enlarged prostate of benign appearance in $22.1 \%$ (51) of patients and normal prostate gland in $15.2 \%$ (35) of patients. Fifty-four patients (23.4\%) were referred for elevation of the total PSA level. Median total PSA was $19.8 \mathrm{ng} / \mathrm{ml}$ (Range: 0.1;5936 ng/ml). Of the 231 patients, 177 (77\%) reported their pathology result. Prostatic adenocarcinoma was the most frequent diagnosis, accounting for $54 \%$ of the patients who reported their result (Fig. 1). Adenocarcinoma was more frequent in 
the age group [60-70 years but there was no statistically significant difference compared to the other age groups $(\mathrm{p}=0.585)$ (Table 2).

Prostatic adenocarcinoma predominated in patients with induration of the prostate or multinodular prostate at digital rectal examination. In contrast, adenomyofibroma predominated in cases where the prostate was normal or benign in appearance on the digital rectal examination (Table 2). The correlation between digital rectal examination and pathology type showed that the digital examination influenced the pathology results $(p=0.000)$. Among the patients with elevated PSA levels, 14 patients had prostatic adenocarcinoma. In patients with prostate adenocarcinoma, $73 \%$ had a PSA level greater than $20 \mathrm{ng} / \mathrm{ml}$ (Table 2). Statistical analysis showed a statistically significant correlation between the level of total PSA and pathology result $(p=0.000)$. The Gleason score of $8(4+4)$ was more frequent and represented $35.7 \%$ of positive biopsy (Table 3 ).

Postbiopsy complication was noted in 16 patients (6.9\%) after a 15-day follow-up. These complications were:

- Dysuria in four patients who progressed well on analgesics

- Persistent Rectorrhagia of low abundance in a patient with spontaneous resolution.

- Acute prostatitis in a patient who required hospitalization and then parenteral antibiotic therapy. The evolution was favorable.

- Acute urinary retention in a patient who required suprapubic catheterization.

- Initial hematuria in five patients who regressed after treatment with hyperdiuresis, with spontaneous resolution. No patient has had a blood transfusion.
Table 3 Distribution of the total and annual incidence of cancer at the localized stage

\begin{tabular}{|c|c|c|c|c|}
\hline \multirow[t]{2}{*}{ Year } & \multicolumn{3}{|c|}{ Localized stage } & \multirow[t]{2}{*}{ Total } \\
\hline & Low risk & Intermediate risk & High risk & \\
\hline 2017 & $2(0.4 \% 0)$ & $1(0.2 \% 0)$ & $2(0.4 \% 0)$ & $5(1.0 \% 0)$ \\
\hline 2016 & $1(0.2 \% 0)$ & $2(0.3 \% 0)$ & $3(0.5 \% 0)$ & $6(1.0 \% 0)$ \\
\hline 2015 & $1(0.2 \% 0)$ & $3(0.5 \% 0)$ & $4(0.7 \% 0)$ & $8(1.5 \%$ oo) \\
\hline 2014 & $0(0.0 \% 0)$ & $5(0.8 \% 0)$ & $9(1.4 \% 0)$ & $14(2.2 \% 0)$ \\
\hline 2013 & $4(0.6 \% 0)$ & $1(0.2 \% 0)$ & $8(1.3 \%)$ & $13(2.0 \% 0)$ \\
\hline Total & $8(0.3 \% 0)$ & $12(0.4 \%)$ & $26(0.9 \% 0)$ & 46 (1.6\%o) \\
\hline
\end{tabular}

\section{Discussion}

Prostate biopsy is an essential procedure for the diagnosis of prostate cancer, with the exception of cases of cancer discovered on pathology in endoscopic resection chips or prostatic specimen for benign prostate surgery. In our series, the rate of cancer detection in cases of an abnormal prostate on digital rectal examination was similar to that obtained by Cros et al. [7] and Barthelemy et al. [8] who found prostate cancer in $61 \%$ and $67 \%$ of their patients, respectively. In fact, digital rectal examination alone can show a suspicion of prostate cancer in more than $50 \%$ of cases, especially in locally advanced cases, but in the other end, 23 to $45 \%$ of cancers would be ignored if the indications for biopsies were based solely on the digital rectal examination because some tumors do not cause palpable changes [9]. The determination of total PSA remains the biological reference test for prostate cancer screening in our setting. Biopsy prompted by a total PSA greater than $4 \mathrm{ng} / \mathrm{ml}$ yields a detection of cancer of nearly $50 \%$ with a positive predictive value of $32 \%$ [10]. By coupling the digital rectal examination and the total PSA, the cancer detection is almost $60 \%$ with a positive predictive value of $48 \%$ [10]. Total PSA is superior to digital rectal examination in terms of sensitivity (72.1\% vs $53.2 \%$ ), specificity ( $93.2 \%$ vs $83.6 \%$ ) and positive predictive value ( $25.1 \%$ vs $17.8 \%$ ), but the use of total PSA alone is less effective than the combination of the

Table 2 Distribution of the total and annual incidences of cancer by stage

\begin{tabular}{llllll}
\hline Year & \multicolumn{2}{l}{ Staging } & & Total (\%) \\
\cline { 2 - 5 } & Localized stage (\%) & Locally advanced stage (\%) & Metastatic stage (\%) & No classified (\%) \\
\hline 2017 & $5(1.0)$ & $3(0.6)$ & $27(5.3)$ & $5(1.0)$ & $4(2.2)$ \\
2016 & $6(1.0)$ & $2(0.3)$ & $12(2.0)$ & $13(2.2)$ & $33(5.5)$ \\
2015 & $8(1.5)$ & $3(0.5)$ & $19(3.4)$ & $9(1.6)$ & $39(7.0)$ \\
2014 & $14(2.2)$ & $3(0.5)$ & $17(2.7)$ & $19(1.4)$ & $43(6.9)$ \\
2013 & $13(2.0)$ & $2(0.3)$ & $94(3.2)$ & $46(1.6)$ & $19(6.9)$ \\
Total & $46(1.6)$ & $13(0.4)$ & & & $19(6.8)$ \\
\hline
\end{tabular}


two [10]. These data were confirmed by our series that showed that an anomaly of the prostate on rectal examination and/or an increase in the level of total PSA had a significant influence on the prostate biopsy result. The combination of a high total PSA and abnormal DRE gives more precision on the indication of the biopsy. Transrectal ultrasound-guided biopsy has the advantages of providing information on the size and shape of the prostate and showing suspicious lesions in the prostate and seminal vesicles. It also allows a precise targeting of the biopsy. An endorectal probe with a frequency of 5 to $10 \mathrm{MHz}$ must be used. Several studies have compared the effectiveness of transrectal biopsy and transperineal biopsy. But no study has shown any superiority of one technique over the other. While Shinghal et al. [11] found that transperineal ultrasound-guided biopsy is less accurate than the transrectal biopsy, Terris et al. [12] in their study concluded that the transperineal approach provided a visualization of the prostate and a calculation of its volume equivalent to that of the transrectal approach, but the hypoechoic suspicious areas were not detected by the transperineal route. Transperineal ultrasound-guided biopsy is an alternative to the transrectal ultrasound-guided biopsy and offered if the rectum cannot be accessed naturally. With the 12-core sampling scheme used in our series, the detection rate was $54 \%$. The option of carrying out an initial biopsy scheme of more than 12 samples does not significantly increase the detection rate. However, Eskew et al. [13] showed that their protocol based on biopsy in five zones with 13-18 cores sampled increases the detection rate up to $35 \%$ compared to the standard protocol. Much research has been made to improve the performance of biopsy including the sampling of other areas. Terris et al. [12] found that the side biopsy was accompanied by high efficiency in patients with a palpable nodule or hypoechoic lesions of the lateral portion of the prostate and in patients who already had negative random biopsies. The accuracy of ultrasound-guided biopsy with a sensitivity and positive predictive value greater than the digitally guided biopsy could explain the rate of positive biopsy. From a review compiling 639 cases of negative digitally guided biopsies with subsequent ultrasound-guided biopsy, Fortunoff et al. [14] identified $12.8 \%$ of cancer cases, while Hodge et al. [15] and Rifkin et al. [16] noted $53.5 \%$ and $39.3 \%$ of false negatives, respectively. The complications of transrectal prostate biopsy are generally of limited gravity, if antibiotic prophylaxis is administered. In the literature, in the absence of antibiotic prophylaxis, there are between 4 and $25 \%$ of post-biopsy urinary tract infections and 0 to $7 \%$ of severe infections. With antibiotic prophylaxis, the proportion of all infectious complications decreases to $0-9 \%$ [17]. Gram-negative bacilli (E. coli) are the most frequent causes of post-biopsy urinary tract infections $[17,18]$. Resistance to fluoroquinolones is associated with $40 \%$ of complications in the series by Duboureau $\mathrm{H}$ et al. [18]. The complication rate varies in the literature from 3 to $23 \%$ of cases [14, 15, 19]. Infectious and hemorrhagic complications are the main complications of prostate biopsy, which has been confirmed by our series. A $6.9 \%$ complication rate was found in our series. this rate is low compared to those found in the literature $[16,20]$. This difference in the infection rates could be explained by the rectal preparation and the antibiotic prophylaxis which were systematic in our patients.

\section{Conclusion}

Ultrasound-guided transrectal prostate biopsy is an appropriate indication for the diagnosis of prostate cancer in terms of pathologic accuracy and relatively lower morbidity. In our series, the cancer detection rate was significant and the complications rate was acceptable at $6.9 \%$.

\section{Abbreviations \\ MRI: Magnetic resonance imaging; PSA: Prostate-specific antigen; LUTS: Symp- toms of lower urinary tract.}

\section{Acknowledgements}

We thank all the urology staff of the Hopital General Idrissa Pouye.

\section{Authors' contributions}

MoN, MJ, MaN, LN and SMG contributed to data collection, article writing, validation of the version to be published. STF, SCNK, NSN, MMM, EHMD, ILM and IL contributed to data collection. All authors read and approved the final manuscript.

Funding

There is no source of funding.

\section{Availability of data and materials}

The datasets used and/or analyzed during the current study are available from the corresponding author.

\section{Declaration}

\section{Ethics approval and consent to participate}

This study was approved by the ethics committee of Hopital General Idrissa Pouye de Grand Yoff. Since it was a retroscopic review, consent was not required.

\section{Consent for publication}

Not applicable.

\section{Competing interests}

The authors declare that they have no confict of interest.

\section{Author details}

1 Service d'urologie CHU Aristide Le Dantec de Dakar, Dakar, Senegal. ${ }^{2}$ Service d'urologie Hôpital Général Idrissa Pouye, Dakar, Senegal. ${ }^{3}$ Service d'urologie Hôpital Principal de Dakar, Dakar, Senegal. ${ }^{4}$ Département d'Urologie - UFR des Sciences de la Santé, Université de Thiès, Thiès, Senegal. 
Received: 7 July 2020 Accepted: 28 March 2021

Published online: 07 April 2021

\section{References}

1. AUBERT J (1992) Complications des biopsies prostatiques. Analyse d'une série de 4764 biopsies. Prog Urol, (2): 484-487

2. Mondet F, Boyer C, Oddou J-H, Corsois L, Collomb D (2009) La mention systématique d'un indice de qualité dans les comptes rendus de biopsies prostatiques influence les pratiques professionnelles. Prog Urol 19(11):825-829

3. Epstein Jl, Walsh PC, Carmichael M, Brendler CB (1994) Pathologic and clinical findings to predict tumor extent of nonpalpable (stage T1C) prostate cancer. JAMA 271(5):368-374

4. Presti JC (2009) Repeat prostate biopsy — when, where, and how. Urol Oncol Semin Orig Investig 27(3):312-314

5. Schoots IG, Roobol MJ, Nieboer D, Bangma CH, Steyerberg EW, Hunink MGM (2015) Magnetic resonance imaging-targeted biopsy may enhance the diagnostic accuracy of significant prostate cancer detection compared to standard transrectal ultrasound-guided biopsy: a systematic review and meta-analysis. Eur Urol 68(3):438-450

6. Mbassi AA, Magny ET, Douanla DE, Kamga J, Mekeme J, Jiatsa NLR et al (2020) Comparative Study of Digit-Guided Versus Echo-Guided Prostate Biopsies in Diagnosing Prostate Cancer at Yaounde Central Hospital and at Le Centre Médical La Cathedrale - Cameroon. J Dans Oncol Res 1(1):103

7. Cros L, Fehr A, Charlon R (2005) Etude des biopsies prostatiques : indication, réalisation de la biopsie et qualité du compte-rendu d'anatomie pathologique. Rev Med Ass Maladie 36(4):313-322

8. Benatta M, Mehdid M, Benhatchi N, Djazouli MA, Boualga K (2012) RésuItats de la biopsie prostatique chez les patients algériens avec un PSA élevé et/ou un toucher rectal suspect. Afr J Urol 18(3):138-142

9. Fournier G, Valeri A, Mangin P, Cussenot O (2004) Cancer de la prostate. Diagnostic et bilan d'extension Ann Urol 38(5):207-224
10. La LE (1996) ponction biopsie de prostate. Prog Urol 6:507-518

11. Shinghal R, Terris MK (1999) Limitations of transperineal ultrasoundguided prostate biopsies. Urology 54(4):706-708

12. Terris MK, Hammerer PG, Nickas ME (1998) Comparison of ultrasound imaging in patients undergoing transperineal and transrectal prostate ultrasound. Urology 52(6):1070-1072

13. Eskew LA, Bare RL, McCullough DL (1997) Systematic 5 region prostate biopsy is superior to sextant method for diagnosing carcinoma of the prostate. J Urol 157(1):199-202

14. Fortunoff S (1962) Needle biopsy of the prostate: a review of 346 biopsies. J Urol 87:159-163

15. Hodge KK, McNeal JE, Stamey TA (1989) Ultrasound guided transrectal core biopsies of the palpably abnormal prostate. J Urol 142(1):66-70

16. Rifkin MD, Alexander AA, Pisarchick J, Matteucci T (1991) Palpable masses in the prostate: superior accuracy of US-guided biopsy compared with accuracy of digitally guided biopsy. Radiology 179(1):41-42

17. Matlaga BR, Eskew LA, McCullough DL (2003) Prostate biopsy: indications and technique. J Urol 169(1):12-19

18. Duboureau H, Achkar K, Stephan R, Schmit JL, Saint F (2017) Écologie et résistances aux fluoroquinolones dans les complications infectieuses urinaires fébriles (CIUF) après biopsies de prostate : étude rétrospective portant sur 466 biopsies. Progrès en Urologie mai 27(6):345-350

19. Barthelemy Y, Gasman D, Bellot J, Chopin D, Abbou CC (1996) Valeur pronostique d'une unique biopsie prostatique échoguidée positive sur le volume tumoral et le caractère intra capsulaire de l'adénocarcinome prostatique. Prog Urol 6:920-925

20. Rodríguez LV, Terris MK (1998) Risks and complications of transrectal ultrasound guided prostate needle biopsy: a prospective study and review of the literature. J Urol 160(6 Pt 1):2115-2120

\section{Publisher's Note}

Springer Nature remains neutral with regard to jurisdictional claims in published maps and institutional affiliations.

\section{Submit your manuscript to a SpringerOpen ${ }^{\circ}$ journal and benefit from:}

- Convenient online submission

- Rigorous peer review

- Open access: articles freely available online

- High visibility within the field

- Retaining the copyright to your article

Submit your next manuscript at springeropen.com 